\title{
Recent Development of Corrosion Protection Strategy Based on Mussel Adhesive Protein
}

\author{
Fan Zhang* and Jinshan Pan \\ Division of Surface and Corrosion Science, Department of Chemistry, KTH Royal Institute of Technology, Stockholm, Sweden
}

Many of traditional anti-corrosion approaches using chromate are effective but hazardous to natural environment and human health, so development of green and effective alternatives is desirable. One of the mussel adhesive proteins derived from mussel byssus presents extraordinary adhesion to steel surface and exhibits film-forming and corrosion inhibition properties. Novel strategies for enhancing the corrosion inhibition of steel by the protein have been demonstrated recently. The protein together with ceria nanoparticles presents a great potential for the development of new corrosion inhibitors and thin films that are "green" and "effective," and have "smart" protection properties.

OPEN ACCESS

Edited by:

Flavio Deflorian,

University of Trento, Italy

Reviewed by:

Benjamin Salas Valdez,

Universidad Autónoma de Baja

California, Mexico

Changdong Gu,

Zhejiang University, China

Isolda Costa,

Instituto de Pesquisas Energéticas e

Nucleares (CNEN), Brazil

*Correspondence:

Fan Zhang

fanzhang@kth.se

Specialty section:

This article was submitted to

Environmental Materials,

a section of the journal

Frontiers in Materials

Received: 28 June 2019

Accepted: 12 August 2019

Published: 27 August 2019

Citation:

Zhang F and Pan J (2019) Recent Development of Corrosion Protection

Strategy Based on Mussel Adhesive

Protein. Front. Mater. 6:207.

doi: 10.3389/fmats.2019.00207
Keywords: mussel adhesive protein, film-forming corrosion inhibitor, corrosion inhibition, self-healing (self-repairing), Mefp-1

\section{INTRODUCTION}

Metal corrosion is a serious material degradation problem from both economic and structural integrity standpoints. Carbon steel is the most widely used metal material, and corrosion of carbon steel occurs in almost all practical environments, but it can be largely controlled by suitable strategies. Because of hazardous nature of traditional corrosion inhibitors, development of green and effective alternatives is desirable.

Mussel adhesive proteins (MAPs), derived from Mytilus foot, have been suggested as a basis for environmentally friendly adhesives. Chemical characterization of MAPs started in early eighties (Waite, 1983a). So far at least six adhesive proteins have been extracted and identified from several species of mussel, and named as Mytilus foot proteins ( $M f p$, plus a number indicating the chronological order of identification; Zhao et al., 2006). These proteins present a basic isoelectric point due to the high content of posttranslational modified amino acid residues (Waite and Tanzer, 1980; Waite, 1983b). They are classified into three groups according to their function in the mussel foot: cuticle protein, adhesive protein, and structural protein. The 3, 4-dihydroxyphenylalanine (DOPA) has been recognized as the primary residue response for both adhesion and cohesion properties of the proteins.

\section{DIFFERENT MUSSEL ADHESIVE PROTEINS}

\section{Cuticle Protein}

$M f p-1$ is the only protein associated with the protective outer cuticle of byssal threads including plaques (Sun and Waite, 2005). It is the largest foot protein that has a molecular weight of about 108 $\mathrm{kDa}$ (Filpula et al., 1990; Holten-Andersen et al., 2009). It's molecule structure is open and extended in the acidic solution with minimized secondary structure (Williams et al., 1989), and consists of 75-80 repetitive decapeptide units with about $15 \mathrm{~mol} \%$ of DOPA in the sequence (Waite, 2002). 


\section{Structural Protein}

$M f p-2,4,6$ serve as structural proteins in mussel foot. Mfp2 is the structural component of the plaque matrix. It has a molecule weight about $42-47 \mathrm{kDa}$ and rich in disulfide containing cysteine of about $6 \mathrm{~mol} \%$ in repetitive sequence (Rzepecki et al., 1992). Pure Mfp-2 is prone to form aggregates upon prolonged storage (Rzepecki et al., 1992). Mfp-4 is the junction between byssal plaque and thread. It has a mass of about $93 \mathrm{kDa}$ and contains an $\mathrm{N}$-terminal histidine-rich domain and a C-terminal domain, which can bound strongly to $\mathrm{Cu}^{2+}$, and calcium-binding plaque proteins, respectively (Zhao and Waite, 2006). $M f p-6$ acts as a conjunction of the interfacial proteins and the plaque matrix protein, and antioxidant of the interfacial proteins to maintain adhesive property of the mussel plaques in oxidative environment (Nicklisch et al., 2016). It has a mass of $11.6 \mathrm{kDa}$, and contains a high level of tyrosine $(20 \mathrm{~mol} \%)$ and cysteine (11 mol\%). All these structural proteins contain limited amount of DOPA about 2-3 mol\% (Nicklisch et al., 2016).

\section{Adhesive Protein}

$M f p-3,5$ are identified as interfacial proteins present at the plaque-substrate interface. They form a primer-like layer at the plaque-substrate interface providing adhesion to the substrate. $M f p-3$ is the smallest one with a mass of about $6 \mathrm{kDa}$ (Papov et al., 1995; Warner and Waite, 1999). Most polymorphic mussel foot protein analogous to Mefp-3 have been identified from mussel species (Floriolli et al., 2000). The variants contain high level of DOPA (20 mol\%) and rich in lysine and glycine. Mfp-5 is also a small protein with a molecular mass of $9 \mathrm{kDa}$ (Waite and Qin, 2001). It has a homogeneous primary sequence that contains the highest content of DOPA (about $30 \mathrm{~mol} \%$ ) amongst all foot proteins, is also rich in lysine $(20 \mathrm{~mol} \%)$ and glycine $(15$ mol\%), and has a significant number of phosphoserine residues in the sequence. It is found that over $75 \%$ of the DOPA in $M f p-5$ is adjacent to lysine, which can remove hydrated cations from the adhesion interface and promote the approaching of catechol of DOPA to the mineral substrate (Maier et al., 2015). The phosphoserine residues contribute to an enhanced mineralbinding property of $M f p-5$ to calcareous surfaces (Long et al., 1998; Silverman and Roberto, 2007). Therefore, Mfp-5 shows the greatest adhesion than other reported foot proteins. Mfp3 and $M f p-5$ present in a small amount in the mussel plaque (Lee et al., 2011).

Mefp-1, 3, and 5 extracted from Mytilus edulis have shown corrosion inhibition properties for metallic materials. Most studies were conducted with Mefp-1 as corrosion inhibitors in different forms. Only two works have been reported on Mefp-3 and Mefp-5, which were evaluated as dissolved inhibitor against flash rust (Nelson and Hansen, 2016; Hansen et al., 2019). Mefp-3 and Mefp-5 show high auto-oxidation rate in bulk solution due to the short chain (Haemers et al., 2003). These factors make them unfavorable materials for development of corrosion inhibitors. One the other hand, Mefp-1, the best-characterized mussel adhesive protein, naturally functions as a protective cuticle of byssus. It is abundant in mussels and contains high level of DOPA, which provides the molecule controllable adhesive and cohesive properties. The oxidation rate is low at acidic condition
(Haemers et al., 2003, 2005). All these facts make Mefp-1 the most promising candidate for the development of bio-based corrosion protective strategies, and a range of Mepf-1 inhibitors have been developed in recent years. Therefore, this review will be focused on Mefp-1.

\section{SURFACE CHEMISTRY OF MEFP-1}

\section{Adsorption}

Mefp-1 can adsorb strongly on metal and metal oxides and form films on the surface. Mechanisms of the strong adhesion are attributed to displacement of surface-bound water molecules from the target surfaces, and simultaneously formation of catechol-metal coordination and hydrogen bond between the catechol of DOPA and metal atoms of the substrate (Wei et al., 2016). It shows a saturated adsorption of Mefp-1 due to the electrostatic interactions, the maximum adsorption amount is almost independent to the protein concentration, but determined by the aggregation degree (Haemers et al., 2001). The adsorption rate of the protein is highly related to the hydrodynamic radius (Krivosheeva et al., 2012). Therefore, non-aggregate Mefp1 adsorbs faster than Mefp-1 aggregates. For anticorrosion property, multilayer adsorption and film compaction are desired, which may occur on aggregated Mefp-1. This occurs only when the adsorbed layer has undergone a conformational change (Haemers et al., 2002). The adsorption amount of aggregated protein is higher, and the formed film is thicker as compared with the non-aggregated one (Krivosheeva et al., 2013).

\section{Oxidation}

DOPA undergoes auto-oxidation in presence of oxygen (Haemers et al., 2003), or can be oxidized by addition of chemical oxidants or enzyme. Oxidation of DOPA results in formation of oxidative conversions of DOPA-quinone, leading to intermolecular crosslinking ( $\mathrm{Yu}$ et al., 1999). The quinone reversely dismutates to aryloxy free radicals, which then couple and re-oxidize to form coupled diphenols (Burzio and Waite, 2000). The coupling of diphenols results in polymerization of the protein. The polymerization property of DOPA enables the development of highly effective anticorrosion adhesives (Hansen et al., 1998), which can be achieved by adjusting $\mathrm{pH}$, and adding catechol oxidase chemical or enzyme.

Film-forming corrosion inhibitors require both strong affinity to the substrate and low permeation of the corrosive media. Since adhesion and cohesion properties of $M e f p-1$ are dependent on DOPA in reduction and oxidation states, respectively, the enhancement of the cohesion property is obtained on the expense of the adhesion property, therefore, a too extensive oxidation of Mefp-1 film may lead to interfacial failure (Waite, 2002). The crosslinking level of Mefp-1 must be controlled optimally to ensure a good balance between the adhesion and cohesion properties of the inhibitor film.

\section{$\mathrm{pH}$-induced Oxidation}

The $\mathrm{pH}$ of the buffer solution has a strong influence on the aggregation degree of Mefp-1 molecules and the film formation rate on surfaces (Haemers et al., 2001). At higher $\mathrm{pH}$ the 
auto-oxidation rate of $M e f p-1$ is higher, which results in a higher aggregation rate (Haemers et al., 2005). Moreover, at higher $\mathrm{pH}$ the formed protein film appears to be more compact (Zhang, 2013), which can be explained by the enhanced oxidative crosslinking of the DOPA segments in the film. The nearneutral $\mathrm{pH}$ has been demonstrated as the optimal $\mathrm{pH}$ for Mefp-1 film deposition.

\section{Chemical- or Enzyme-Induced Oxidation}

$\mathrm{NaIO}_{4}$ is suggested to be a suitable oxidant to induce crosslinking of Mefp-1 (Hedlund et al., 2009). Treatment of the $M e f p-1$ film in $10 \mathrm{mM} \mathrm{NaIO}_{4}$ solution for 10 min leads to oxidative conversion from DOPA to DOPA-quinone, followed by diphenols coupling (Höök et al., 2001). Therefore, the film becomes a thinner, denser and more uniform (Zhang et al., 2012). Enzyme catalyzes crosslinking of DOPA functional groups in the same oxidative mechanism as the chemical oxidants (Fant et al., 2000). Mushroom tyrosinase has been used to treat the adsorbed Mefp-1, giving an increased corrosion resistance (Nelson and Hansen, 2016).

\section{Complexation}

DOPA can chelate $\mathrm{Fe}^{3+}$ to form complexes (Zeng et al., 2010). In situ observations of Mefp-1 on carbon steel indicate an enhanced adsorption of $M e f p-1$ at local corroding sites (Zhang et al., 2011). The enrichment of Mefp-1 is related to the interaction between DOPA and Fe ions released from the substrate. DOPA is a bidentate through which Mefp-1 can form strong complexes with $\mathrm{Fe}^{3+}$ in mono-, bis-, and triscatecholate- $\mathrm{Fe}^{3+}$ forms, depending on the $\mathrm{pH}$ and catechol/ $/ \mathrm{Fe}^{3+}$ molar ratios.

The tri-DOPA $/ \mathrm{Fe}^{3+}$ complex formation causes a compaction of and removal of the coupled water from the Mefp-1 film. Different types of metal ions can induce metal-ligandcomplexation, whereas $\mathrm{Fe}^{3+}$ is the most investigated, especially with aspect to corrosion inhibition. Since $\mathrm{Fe}^{3+}$ ions can be released from the corroding steel substrate, the complexation with Mefp-1 offers the promise of the protein film with the intrinsic self-healing property (Holten-Andersen et al., 2011).

\section{Electrochemical Tuning}

Mefp-1 adsorption and the film conformation can be reversibly controlled by applying an electrochemical potential (Zhang et al., 2017). The study with Pt substrate has shown that Mefp-1 adsorbs to metal via electrostatic and non-electrostatic interactions. At low potential (hydrogen adsorption-desorption region), Mefp1 adsorption increases with the increasing potential, leading to higher protein coverage of the surface. At medium potential, the pre-adsorbed Mefp-1 film becomes less compact with increasing of potential, forming a thicker layer with higher water content. At high potential (Pt oxidation region), the pre-adsorbed Mefp-1 undergoes oxidative crosslinking, resulting in a film compaction. Moreover, the adsorbed protein film presents a blocking effect on hydrogen adsorption/desorption and Pt oxidation/reduction. The reversible electrochemical reactions of Mefp-1 provide strategies to control corrosion inhibition properties of the protein film.

\section{Combination With Ceria Nanoparticles}

The thin film of ceria $\left(\mathrm{CeO}_{2}\right)$ has shown an enhanced corrosion resistance to metallic substrates (Zhong et al., 2008). Nanoparticles of ceria present more special properties, such as oxygen storage and oxidation power due to the redox reaction (Preda et al., 2011). In the regard of the impact to human health, ceria nanoparticles are not cytotoxic but instead protect cells from oxidative insult (Xia et al., 2008). Moreover, negatively charged ceria nanoparticle can facilitate the multilayer deposition of the positively charged Mefp-1.

Density Function Theory calculations show that catechol is energetically favored to bind strongly to ceria nanoparticles (Zhang et al., 2013). Therefore, ceria nanoparticles can be irreversibly incorporated into the $M e f p-1$ film, to facilitate a continuous build-up of the multilayer of Mefp-1/ceria composites (Sababi et al., 2012). Mefp-1 adsorbs in an extended conformation that allows significant hydrodynamic coupling to the solvent, whereas the incorporation of ceria nanoparticles induces the compaction of the protein layer. As shown in Figure 1, the deposited composite film on carbon steel is heterogeneous with some micro-domains showing coherent enrichment of $\mathrm{Ce}$ (from ceria) and C (from Mefp-1), as well as existence of tri$\mathrm{Fe}^{3+} /$ DOPA complex.

\section{MUSSEL ADHESIVE PROTEIN INSPIRED CORROSION PROTECTION}

\section{Mefp-1 as Dissolved Corrosion Inhibitor}

Mefp-1 has been demonstrated as an effective corrosion inhibitor to carbon steel when dissolved in corrosive solutions (Zhang et al., 2011). The corrosion inhibition mechanism varies depending on the exposure condition. Under acidic condition, the initial corrosion inhibition efficiency is higher in the solution with higher $\mathrm{NaCl}$ concentration. In this situation, the autooxidation of $M e f p-1$ is retarded or proceeds very slowly; therefore, the oxidative crosslinking is negligible. The higher inhibition efficiency is mainly attributed to the enhanced DOPA-Fe ${ }^{3+}$ complexation, due to a higher amount of released $\mathrm{Fe}^{3+}$ in the solution with higher $\mathrm{NaCl}$ concentration. The longer-term corrosion inhibition of Mefp-1, e.g., 7 days, increases with increasing $\mathrm{pH}$, and the efficiency is higher in the solution with less concentrated $\mathrm{NaCl}$ (Zhang, 2013). Clearly, the higher autooxidation level of $M e f p-1$ at higher $\mathrm{pH}$ is the dominant factor for the enhanced corrosion inhibition. At near-neutral $\mathrm{pH}$, the inhibition efficiency increases with exposure time (Zhang et al., 2011). Both the oxidation level of Mefp-1 and the amount of $\mathrm{Fe}^{3+}$ released from the substrate increase with time. Therefore, both the oxidative crosslinking and the DOPA-Fe ${ }^{3+}$ complexation processes enhance the corrosion inhibition.

Furthermore, Mefp-1 has also been reported to provide a certain corrosion inhibition to $304 \mathrm{~L}$ stainless steel and $\mathrm{Al}$, retarding the metal dissolution and pitting corrosion (Hansen et al., 1995; Hansen and McCafferty, 1996).

\section{Pre-formed Mefp-1 Film}

Owing to the good film-forming capacity, Mefp-1 has also been investigated as a pre-formed corrosion inhibition film (Zhang 

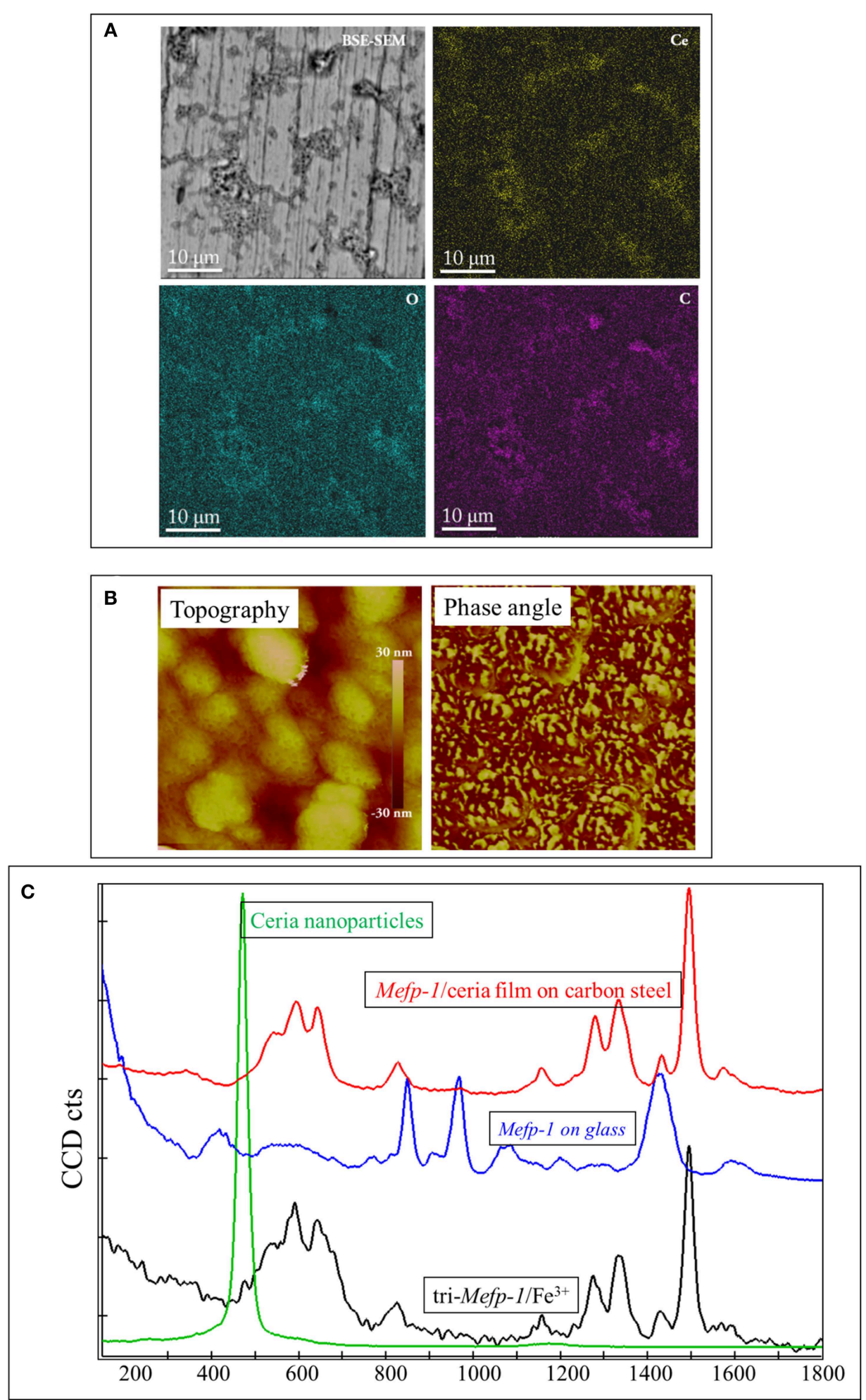

FIGURE 1 | Characterization of the Mefp-1/ceria composite film deposited on the carbon steel. (A) BSE-SEM image and corresponding elemental distribution of Ce, C, and O. (B) AFM topographic image of a compact area (with a size of $500 \mathrm{~nm}$ ) of the composite film, and the corresponding phase image showing two distinct phases. (C) Raman spectrum of the Mefp-1/ceria composite film on the carbon steel, and the reference spectra of the pure Mefp-1 deposited on glass, ceria nanoparticle deposited on glass, and the complex of Mefp-1 with $\mathrm{Fe}^{3+}$. 
et al., 2012). The pre-formed Mefp-1 film provides a certain corrosion protection for short-term exposure, and the corrosion protection can be significantly enhanced by proper oxidation treatment due to the increased compactness. However, the longterm exposure results indicate that the pre-formed Mefp-1 film may degrade with time under the exposure condition. Therefore, for long-term applications, it is desirable to develop other types of $M e f p-1$ films that are more protective and stable during long exposure.

\section{Mefp-1/Ceria Nanocomposite Film}

Nanocomposite films of sub-micron thickness composed of Mefp-1 and ceria nanoparticles have been deposited on carbon steel using alternative immersions and one-stepdipping methods (Sababi et al., 2012; Chen et al., 2016). The nanocomposite films provide excellent corrosion protection for carbon steel for long-term exposure, and the inhibition efficiency increases with exposure time. The increase of the inhibition effect is mainly due to the integration of the corrosion products into the film, as well as enhanced complexation between Mefp-1 in the film and $\mathrm{Fe}$ ions released from the steel surface. Moreover, the Mefp-1/ceria nanocomposite film possesses a certain self-healing ability on carbon steel (Chen et al., 2016). The self-healing ability is attributed to the DOPA of Mefp-1, and the healing process is explained by the fact that $\mathrm{Fe}^{3+}$ released from the surface defects promote the formation of DOPA- $\mathrm{Fe}^{3+}$ complexes in the nanocomposite film, which retards further dissolution and thus the localized corrosion.

\section{Synergistic Effect of Phosphate and Mefp-1/Ceria Composite Film}

Addition of a small amount of $\mathrm{Na}_{2} \mathrm{HPO}_{4}$ into the $\mathrm{NaCl}$ solution results in an enhance corrosion inhibition effect of the Mefp-1/ceria composite film in both short-term and long-term exposures (Zhang et al., 2013). In the phosphate containing solution, the composite film deposited on carbon steel sample presents a two-layer like structure, with the composite film as the inner-layer and a vivianite deposit layer as the outer-layer.

The addition of the phosphate results in ca. one order of magnitude increase of the short-term corrosion resistance of composite film. Moreover, the corrosion resistance of the composite film further increases drastically upon the formation of a continuous phosphate deposit layer that fully covers the surface. In this case the Fe ions released from the steel surface are mostly trapped inside the film due to blockage by the deposited outer layer, and this leads to enhanced complexation between the protein and $\mathrm{Fe}^{3+}$. This consequently causes the compaction of the film and hence a significant increased corrosion protection. Thus, phosphate ions in the solution and the Mefp-1/ceria composite film on the surface have a synergistic effect on the corrosion protection for the steel.

Based on the above-mentioned observations, a nanocomposite film composed of Mefp-1, ceria nanoparticles and phosphate has been developed (Chen et al., 2017), which provides a self-healing effect against pitting corrosion of carbon steel. Moreover, it is found that the inhibition efficiency can be further enhanced by thermal treatment, which leads to an enhanced oxidative crosslinking of Mefp-1 in the composite

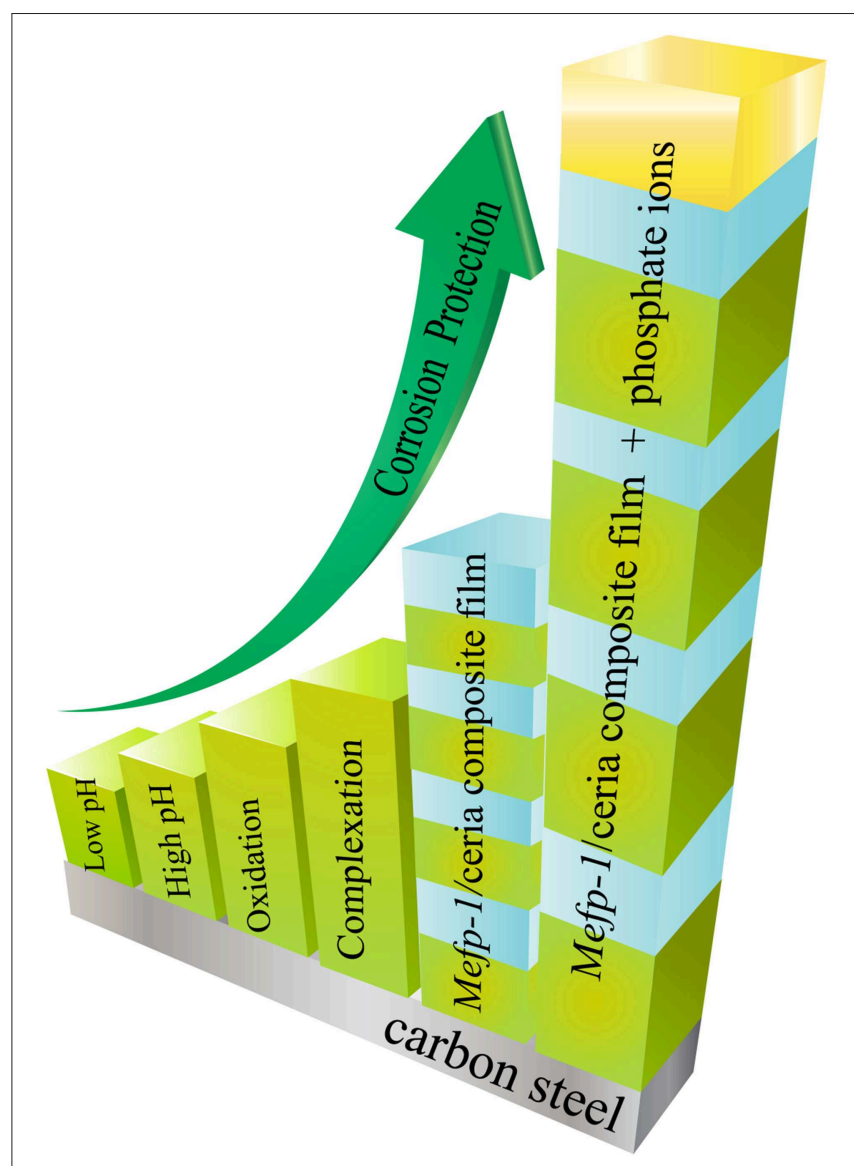

FIGURE 2 | Schematic illustration of the strategies that can be applied to enhance the corrosion inhibition properties of Mefp-1.

film. As a result, the film presents a highly compact structure. Furthermore, industrial applications of the nanocomposite films in reinforced concrete structure has been demonstrated (Zhang et al., 2019).

\section{CONCLUSION}

The unique adhesive and cohesive properties of the mussel adhesive protein have inspired scientific research efforts of investigation and development of a range of new "green" corrosion inhibitors and protective thin films for carbon steel. As summarized in Figure 2, the corrosion inhibition efficiency of the Mefp-1 can be enhanced by means of adjusting $\mathrm{pH}$, ion-induced complexation, and oxidative crosslinking. The adhesion and cohesion properties of the Mefp-1 film can be reversibly tuned via electrochemical potential. Moreover, Mefp-1 can be combined with ceria nanoparticles to form a composite film on steel surface, showing higher corrosion protection efficiency and self-healing properties. Incorporation of phosphate and thermal treatment of the composite film result in a further enhancement of the corrosion inhibition properties.

Based on the fundamental understanding of the chemistry and the obtained corrosion inhibition properties, the mussel adhesive 
protein presents a great potential for the development of new environmentally friendly and sustainable corrosion inhibitors and thin protective films.

\section{AUTHOR CONTRIBUTIONS}

FZ contributed with the writing of the draft. JP revised it critically for important intellectual content.

\section{REFERENCES}

Burzio, L. A., and Waite, J. H. (2000). Cross-linking in adhesive quinoproteins: studies with model decapeptides. Biochemistry 39, 11147-11153. doi: $10.1021 / \mathrm{bi0002434}$

Chen, C., Hou, R., Zhang, F., Dong, S., Claesson, P. M., Lin, C., et al. (2017). Heating-induced enhancement of corrosion protection of carbon steel by a nanocomposite film containing mussel adhesive protein. J. Electrochem. Soc. 164, C188-C193. doi: 10.1149/2.0071706jes

Chen, C., Zhang, F., Lin, C., and Pan, J. (2016). Corrosion protection and self-healing of a nanocomposite film of mussel adhesive protein and $\mathrm{CeO} 2$ nanoparticles on carbon steel. J. Electrochem. Soc. 163, C545-C552. doi: 10.1149/2.0521609jes

Fant, C., Sott, K., Elwing, H., and Hook, F. (2000). Adsorption behavior and enzymatically or chemically induced cross-linking of a mussel adhesive protein. Biofouling 16, 119-132. doi: 10.1080/08927010009378437

Filpula, D. R., Lee, S.-M., Link, R. P., Strausberg, S. L., and Strausberg, R. L. (1990). Structural and functional repetition in a marine mussel adhesive protein. Biotechnol. Prog. 6, 171-177. doi: 10.1021/bp00003a001

Floriolli, R. Y., von Langen, J., and Waite, J. H. (2000). Marine surfaces and the expression of specific byssal adhesive protein variants in Mytilus. Mar. Biotechnol. 2, 352-363. doi: 10.1007/s101269900032

Haemers, S., Koper, G. J., and Frens, G. (2003). Effect of oxidation rate on cross-linking of mussel adhesive proteins. Biomacromolecules 4, 632-640. doi: $10.1021 / \mathrm{bm} 025707 \mathrm{n}$

Haemers, S., van der Leeden, M., Nijman, E., and Frens, G. (2001). The degree of aggregation in solution controls the adsorbed amount of mussel adhesive proteins on a hydrophilic surface. Colloids Surf. A 190, 193-203. doi: 10.1016/S0927-7757(01)00679-3

Haemers, S., van der Leeden, M. C., and Frens, G. (2005). Coil dimensions of the mussel adhesive protein Mefp-1. Biomaterials 26, 1231-1236. doi: 10.1016/j.biomaterials.2004.04.032

Haemers, S., van der Leeden, M. C., Koper, G. J., and Frens, G. (2002). Crosslinking and multilayer adsorption of mussel adhesive proteins. Langmuir 18, 4903-4907. doi: 10.1021/la025626c

Hansen, D., Dexter, S., and Waite, J. (1995). The inhibition of corrosion of S30403 stainless steel by a naturally occurring catecholic polymer. Corrosion Sci. 37, 1423-1441. doi: 10.1016/0010-938X(95)00050-T

Hansen, D. C., Corcoran, S. G., and Waite, J. H. (1998). Enzymatic tempering of a mussel adhesive protein film. Langmuir 14, 1139-1147. doi: 10.1021/la970881w

Hansen, D. C., and McCafferty, E. (1996). The effect of various naturally occurring metal-binding compounds on the electrochemical behavior of aluminum. J. Electrochem. Soc. 143, 114-119. doi: 10.1149/1.1836394

Hansen, D. C., Zimlich, K. R., and Bennett, B. N. (2019). Inhibition of flash rusting of HY 80 by a mussel adhesive protein: characterizing the interaction of MeFP-5 with a high strength low alloy steel. Electrochim. Acta 301, 411-420. doi: $10.1016 /$ j.electacta.2019.01.145

Hedlund, J., Andersson, M., Fant, C., Bitton, R., Bianco-Peled, H., Elwing, H., et al. (2009). Change of colloidal and surface properties of Mytilus edulis foot protein 1 in the presence of an oxidation ( $\mathrm{NaIO} 4)$ or a complex-binding $(\mathrm{Cu} 2+)$ agent. Biomacromolecules 10, 845-849. doi: 10.1021/bm801325j

Holten-Andersen, N., Harrington, M. J., Birkedal, H., Lee, B. P., Messersmith, P. B., Lee, K. Y. C., et al. (2011). pH-induced metal-ligand cross-links inspired by mussel yield self-healing polymer networks with near-covalent elastic moduli. Proc. Natl. Acad. Sci. 108, 2651-2655. doi: 10.1073/pnas.1015862108

\section{ACKNOWLEDGMENTS}

The authors greatly acknowledge the financial supports from the Swedish Foundation for International Cooperation in Research and Higher Education (STINIT project for SwedishChina collaboration, grant no CH2017-7255). Moreover, FZ acknowledge a seed funding from KTH for allowing collaborative research in the field.

Holten-Andersen, N., Zhao, H., and Waite, J. H. (2009). Stiff coatings on compliant biofibers: the cuticle of mytilus californianus byssal threads. Biochemistry 48, 2752-2759. doi: 10.1021/bi900018m

Höök, F., Kasemo, B., Nylander, T., Fant, C., Sott, K., and Elwing, H. (2001). Variations in coupled water, viscoelastic properties, and film thickness of a Mefp-1 protein film during adsorption and cross-linking: a quartz crystal microbalance with dissipation monitoring, ellipsometry, and surface plasmon resonance study. Anal. Chem. 73, 5796-5804. doi: 10.1021/ac01 06501

Krivosheeva, O., Dedinaite A., and Claesson, P. M. (2012). Adsorption of Mefp1: Influence of $\mathrm{pH}$ on adsorption kinetics and adsorbed amount. J. Colloid Interface Sci. 379, 107-113. doi: 10.1016/j.jcis.2012.04.040

Krivosheeva, O., Dedinaite, A., and Claesson, P. M. (2013). Salt-and pHinduced desorption: comparison between non-aggregated and aggregated mussel adhesive protein, Mefp-1, and a synthetic cationic polyelectrolyte. $J$. Colloid Interface Sci. 408, 82-86. doi: 10.1016/j.jcis.2013.07.015

Lee, B. P., Messersmith, P. B., Israelachvili, J. N., and Waite, J. H. (2011). Mussel-inspired adhesives and coatings. Ann. Rev. Mater. Res. 41, 99-132. doi: 10.1146/annurev-matsci-062910-100429

Long, J. R., Dindot, J. L., Zebroski, H., Kiihne, S., Clark, R. H., Campbell, A. A., et al. (1998). A peptide that inhibits hydroxyapatite growth is in an extended conformation on the crystal surface. Proc. Natl. Acad. Sci. 95, 12083-12087. doi: 10.1073/pnas.95.21.12083

Maier, G. P., Rapp, M. V., Waite, J. H., Israelachvili, J. N., and Butler, A. (2015). Adaptive synergy between catechol and lysine promotes wet adhesion by surface salt displacement. Science 349, 628-632. doi: 10.1126/science.aab0556

Nelson, W. F., and Hansen, D. C. (2016). Investigations of mussel adhesive proteins as flash rust inhibitors. J. Electrochem. Soc. 163, C553-C562. doi: 10.1149/2.0541609jes

Nicklisch, S. C., Spahn, J. E., Zhou, H., Gruian, C. M., and Waite, J. H. (2016). Redox capacity of an extracellular matrix protein associated with adhesion in Mytilus californianus. Biochemistry 55, 2022-2030. doi: 10.1021/acs.biochem.6b00044

Papov, V. V., Diamond, T. V., Biemann, K., and Waite, J. H. (1995). Hydroxyarginine-containing polyphenolic proteins in the adhesive plaques of the marine mussel mytilus-edulis. J. Biol. Chem. 270, 20183-20192. doi: $10.1074 /$ jbc. 270.34 .20183

Preda, G., Migani, A., Neyman, K. M., Bromley, S. T., Illas, F., and Pacchioni, G. (2011). Formation of superoxide anions on ceria nanoparticles by interaction of molecular oxygen with Ce3+ sites. J. Phys. Chem. C 115, 5817-5822. doi: $10.1021 /$ jp111147y

Rzepecki, L. M., Hansen, K. M., and Waite, J. H. (1992). Characterization of a cystine-rich polyphenolic protein family from the blue mussel Mytilus edulis L. Biol. Bull. 183, 123-137. doi: 10.2307/1542413

Sababi, M., Zhang, F., Krivosheeva, O., Forslund, M., Pan, J., Claesson, P. M., et al. (2012). Thin composite films of mussel adhesive proteins and ceria nanoparticles on carbon steel for corrosion protection. J. Electrochem. Soc. 159, C364-C371. doi: 10.1149/2.061208jes

Silverman, H. G., and Roberto, F. F. (2007). Understanding marine mussel adhesion. Mar. Biotechnol. 9, 661-681. doi: 10.1007/s10126-007-9053-X

Sun, C., and Waite, J. H. (2005). Mapping chemical gradients within and along a fibrous structural tissue, mussel byssal threads. J. Biol. Chem. 280, 39332-39336. doi: 10.1074/jbc.M508674200

Waite, J. H. (1983a). Adhesion in byssally attached bivalves. Biol. Rev. Cambridge Philos. Soc. 58, 209-231. doi: 10.1111/j.1469-185X.1983.tb00387.x 
Waite, J. H. (1983b). Evidence for a repeating 3,4-dihydroxyphenylalanine- and hydroxyproline-containing decapeptide in the adhesive protein of the mussel, Mytilus edulis L. J. Biol. Chem. 258, 2911-2915.

Waite, J. H. (2002). Adhesion à la moule. Integr. Compar. Biol. 42, 1172-1180. doi: $10.1093 / \mathrm{icb} / 42.6 .1172$

Waite, J. H., and Qin, X. (2001). Polyphosphoprotein from the adhesive pads of Mytilus edulis. Biochemistry 40, 2887-2893. doi: 10.1021/bi002718x

Waite, J. H., and Tanzer, M. L. (1980). The bioadhesive of Mytilus byssus: A protein containing L-DOPA. Biochem. Biophys. Res. Commun. 96, 1554-1561. doi: 10.1016/0006-291X(80)91351-0

Warner, S., and Waite, J. (1999). Expression of multiple forms of an adhesive plaque protein in an individual mussel, Mytilus edulis. Mar. Biol. 134, 729-734. doi: $10.1007 / \mathrm{s} 002270050589$

Wei, W., Petrone, L., Tan, Y., Cai, H., Israelachvili, J. N., Miserez, A., et al. (2016). An underwater surface-drying peptide inspired by a mussel adhesive protein. Adv. Funct. Mater. 26, 3496-3507. doi: 10.1002/adfm.201600210

Williams, T., Marumo, K., Waite, J. H., and Henkens, R. W. (1989). Mussel glue protein has an open conformation. Arch. Biochem. Biophys. 269, 415-422. doi: 10.1016/0003-9861(89)90125-2

Xia, T., Kovochich, M., Liong, M., Mädler, L., Gilbert, B., Shi, H., et al. (2008). Comparison of the mechanism of toxicity of zinc oxide and cerium oxide nanoparticles based on dissolution and oxidative stress properties. ACS Nano 2, 2121-2134. doi: $10.1021 / \mathrm{nn} 800511 \mathrm{k}$

Yu, M., Hwang, J., and Deming, T. J. (1999). Role of L-3, 4-dihydroxyphenylalanine in mussel adhesive proteins. J. Am. Chem. Soc. 121, 5825-5826. doi: $10.1021 /$ ja $990469 y$

Zeng, H., Hwang, D. S., Israelachvili, J. N., and Waite, J. H. (2010). Strong reversible $\mathrm{Fe} 3+$-mediated bridging between dopa-containing protein films in water. Proc. Natl. Acad. Sci. 107, 12850-12853. doi: 10.1073/pnas.1007416107

Zhang, F. (2013). The Mussel Adhesive Protein (Mefp-1): A GREEN Corrosion Inhibitor. KTH Royal Institute of Technology.

Zhang, F., Brinck, T., Brandner, B. D., Claesson, P. M., Dedinaite, A., and Pan, J. (2013). In situ confocal Raman micro-spectroscopy and electrochemical studies of mussel adhesive protein and ceria composite film on carbon steel in salt solutions. Electrochim. Acta 107, 276-291. doi: 10.1016/j.electacta.2013.05.078
Zhang, F., Chen, C., Hou, R., Li, J., Cao, Y., Dong, S., et al. (2019). Investigation and application of mussel adhesive protein nanocomposite film-forming inhibitor for reinforced concrete engineering. Corrosion Sci. 153, 333-340. doi: 10.1016/j.corsci.2019.03.023

Zhang, F., Pan, J., and Claesson, P. M. (2011). Electrochemical and AFM studies of mussel adhesive protein (Mefp-1) as corrosion inhibitor for carbon steel. Electrochim. Acta 56, 1636-1645. doi: 10.1016/j.electacta.2010.10.033

Zhang, F., Pan, J., Claesson, P. M., and Brinck, T. (2012). Electrochemical, Atomic Force Microscopy and Infrared Reflection Absorption Spectroscopy studies of pre-formed mussel adhesive protein films on carbon steel for corrosion protection. Thin Solid Films 520, 7136-7143. doi: 10.1016/j.tsf.2012. 07.115

Zhang, F., Xie, G., and Pan, J. (2017). Tunable adsorption and film formation of mussel adhesive protein by potential control. Langmuir 33, 8749-8756. doi: 10.1021/acs.langmuir.6b04125

Zhao, H., Robertson, N. B., Jewhurst, S. A., and Waite, J. H. (2006). Probing the adhesive footprints of Mytilus californianus byssus. J. Biol. Chem. 281, 11090-11096. doi: 10.1074/jbc.M510792200

Zhao, H., and Waite, J. H. (2006). Proteins in load-bearing junctions: the histidinerich metal-binding protein of mussel byssus. Biochemistry 45, 14223-14231. doi: 10.1021/bi061677n

Zhong, X., Li, Q., Hu, J., and Lu, Y. (2008). Characterization and corrosion studies of ceria thin film based on fluorinated AZ91D magnesium alloy. Corrosion Sci. 50, 2304-2309. doi: 10.1016/j.corsci.2008.05.016

Conflict of Interest Statement: The authors declare that the research was conducted in the absence of any commercial or financial relationships that could be construed as a potential conflict of interest.

Copyright $(\odot) 2019$ Zhang and Pan. This is an open-access article distributed under the terms of the Creative Commons Attribution License (CC BY). The use, distribution or reproduction in other forums is permitted, provided the original author(s) and the copyright owner(s) are credited and that the original publication in this journal is cited, in accordance with accepted academic practice. No use, distribution or reproduction is permitted which does not comply with these terms. 